\title{
Household catastrophic medical expenses in eastern China: determinants and policy implications
}

\author{
Xiaohong Lii, Jay J Shen², Jun Lu', Ying Wang ${ }^{1}$, Mei Sun ${ }^{1}$, Chengyue Li ${ }^{1}$, Fengshui Chang ${ }^{1}$ and Mo Hao ${ }^{1 *}$
}

\begin{abstract}
Background: Much of research on household catastrophic medical expenses in China has focused on less developed areas and little is known about this problem in more developed areas. This study aimed to analyse the incidence and determinants of catastrophic medical expenses in eastern China.

Methods: Data were obtained from a health care utilization and expense survey of 11,577 households conducted in eastern China in 2008. The incidence of household catastrophic medical expenses was calculated using the method introduced by the World Health Organization. A multi-level logistic regression model was used to identify the determinants.

Results: The incidence of household catastrophic medical expenses in eastern China ranged from 9.24\% to 24.79\%. Incidence of household catastrophic medical expenses was lower if the head of household had a higher level of education, labor insurance coverage, while the incidence was higher if they lived in rural areas, had a family member with chronic diseases, had a child younger than 5 years old, had a person at home who was at least 65 years old, and had a household member who was hospitalized. Moreover, the impact of the economic level on catastrophic medical expenses was non-linear. The poorest group had a lower incidence than that of the second lowest income group and the group with the highest income had a higher incidence than that of the second highest income group. In addition, region was a significant determinant.
\end{abstract}

Conclusions: Reducing the incidence of household catastrophic medical expenses should be one of the priorities of health policy. It can be achieved by improving residents' health status to reduce avoidable health services such as hospitalization. It is also important to design more targeted health insurance in order to increase financial support for such vulnerable groups as the poor, chronically ill, children, and senior populations.

\section{Background}

Out-of-pocket payment for medical services is very high in most developing countries and the household's catastrophic medical expenses are being used as one of the indicators measuring whether out-of-pocket payment disrupts material living standards of individuals and households [1,2]. Reducing incidence of household catastrophic medical expenses is one of the objectives of health policy [1]. Understanding the incidence of catastrophic medical expenses and its determinants is the

\footnotetext{
* Correspondence: haomo03@fudan.edu.cn

${ }^{1}$ Research Institute of Health Development Strategies, School of Public Health, Fudan University, Shanghai, China

Full list of author information is available at the end of the article
}

basis for developing effective health policies to address this problem.

Studies on household catastrophic medical expenses in China have so far focused on relatively less developed regions, central China and western China, especially rural areas in these regions [3]. Most of the studies merely focus on descriptive analysis on the situation and efforts of identifying underlying factors that are associated with catastrophic medical expenses have been lacking [3]. Furthermore, based on our literature review, studies on this problem in eastern China, a relatively developed region, are rare. Sun and colleagues examined the effect of the New Cooperative Medical Scheme on catastrophic medical expenses but their analysis did not consider socioeconomic factors [4].

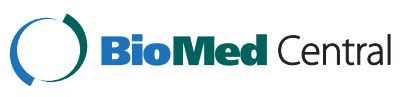


It has been reported that both affluent and poor residents in eastern China are concerned about the high out-of-pocket payment of medical expenses that can seriously compromise their living standard [5]. However, the incidence and determinants of household catastrophic medical expenses in this region remain unknown. It is important to identify the influencing factors, which helps find the specific approaches to solve the problems. This study estimated the incidence of household catastrophic medical expenses and then identified its associated factors. In addition, comparison between eastern China and other part of China is also conducted.

\section{Methods}

\section{Study setting}

It was a cross-section survey conducted in eastern China. We conducted a health care utilization and expenses survey in three cities, Shanghai, Changzhou in Jiangsu province, and Weifang in Shandong province, in eastern China in 2008. The data are not openly available to the public. Shanghai is a well-developed municipality (equivalent to province) directly under control of the central government. In 2010, The national per capita GDP was 29,992 in the mainland that year [6]. Shanghai was ranked the first in terms of per capita GDP among the 31 provinces or municipalities in the mainland in China, with a GDP per capita of 76,074 yuan [6]. Shanghai city consists of 8 central districts and 9 suburban districts. Because the economic level of the central districts is very high and there are only urban residents in the central districts, they are not ideal representatives for eastern China. Among the 9 suburban districts, we selected Jiading district as the sample area with relatively high economic level among the suburban districts, which could better represent the well-developed areas in eastern China. Jiangsu province and Shandong province were ranked the $4^{\text {th }}(52,840$ yuan $)$ and $9^{\text {th }}(41,106$ yuan) on per capital GDP, respectively [6]. Changzhou city in Jiangsu province was selected for our survey and its per capita GDP was 67,327 yuan [7]. Weifang city in Shandong province was selected and its per capita GDP was 35,260 yuan in 2010 [8].

\section{Sampling}

After selecting the study areas, Jiading in Shanghai, Changzhou in Jiangsu and Weifang in Shandong, we sampled the residents using a stratified method. In recent years, though town merging has taken place in the three areas, there has not been a significant change in residents' daily life. Therefore, we still used the previous allocation of towns when sampling. There were a lot of differences in living standard between residents and rural residents, so we selected urban residents and rural residents respectively, namely, we selected urban residents in Jiading, rural residents in Jiading, rural residents in Changzhou, urban residents in Weifang and rural residents in Weifang, respectively.

We take sampling of rural households in Changzhou as an example to demonstrate the sampling design, sample size calculation and response rate.

In 2008, Changzhou consisted of 5 districts and 2 counties, with 1.2221 million households, and 39\% of the population was rural resident. Rural residents mostly lived in one district (District A) and the two counties (County B and County C). District A, County B and County $\mathrm{C}$ had 23, 19 and 17 towns, respectively. We used the stratified random sampling method. Firstly, all the towns in District A, County B and County $\mathrm{C}$ respectively were divided into 3 tiers in respect to their income levels. In each tier, 2 towns were selected randomly. Secondly, in each of the selected towns, all villages were grouped into three tiers: near to, middle-distance from, and far away from the centre point of the town. In each tier, 3 villages were randomly selected. Finally, 40-60 rural households were randomly selected from each of the villages. The sampling was shown in the Figure 1.

We used the simple random sampling formula to calculate the sample size of rural households in Changzhou, because we only had limited literature and more parameters were needed in the stratified sample size calculation formula. After we got the total sample needed, we allocated the sample size in each selected village using probability proportionate to size sampling (PPS) [9].

The simple random size calculation formula [10]:

$$
n=\frac{u_{\alpha}^{2} \pi(1-\pi)}{\delta^{2}}
$$

Let $\delta=0.025, \mathrm{u}=1.96, \alpha=0.05$. The incidence of catastrophic medical expenses in the literature range from $4 \%$ to $20 \%[3,4,11]$, and we supposed $\pi$ ranged from $4 \%$ to $25 \%$. We got the biggest size of 1152 households. Taking incomplete questionnaires into account, we should survey about 1300 households. The local government wanted to better understand the situation of Changzhou and provided organizational support, and finally we expanded the sample size to 2700 households. Finnaly, according to rural households in Changzhou, 54 villages in 18 towns were selected, and 2703 households were surveyed, and 128 households were excluded due to incomplete data. Therefore the response rate was $95.26 \%$.

Similarly, households in other regions were selected using this stratified method. The sample size of rural households is the smallest compared with other group of households, and reasons are as following. As for rural households in Jiading in Shanghai, the incidence of catastrophic medical expenses was $11.78 \%$ in Shanghai based on the literature [11], and we supposed $\pi$ ranging from 


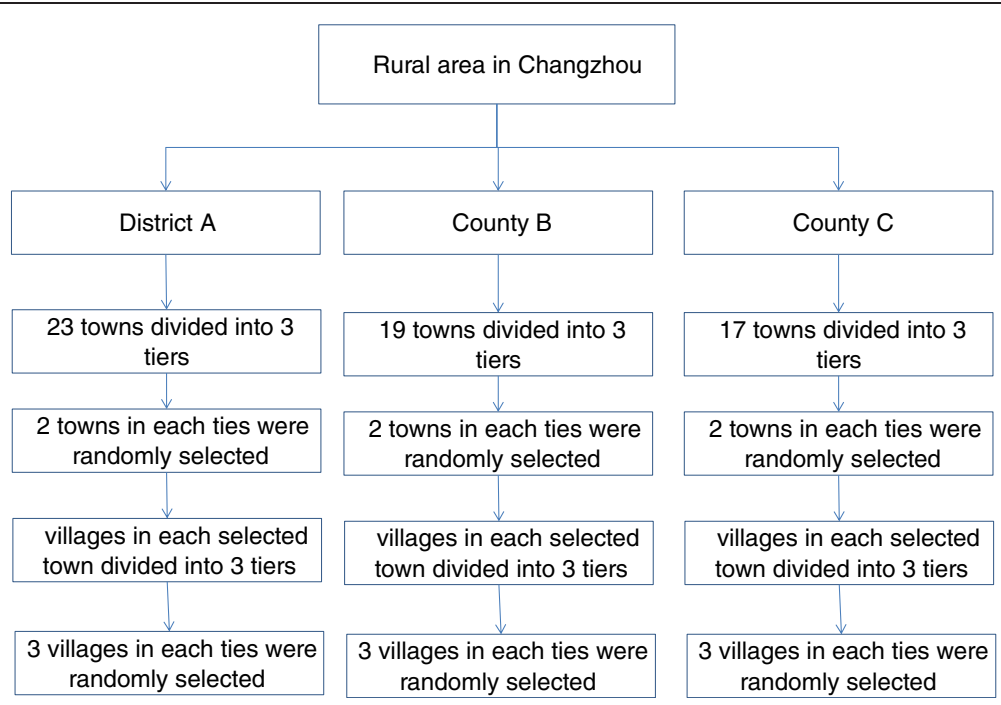

Figure 1 Flow diagram of sampling of rural households in Changzhou.

$7 \%$ to $16 \%$. We got the biggest size of 784 households. Taking incomplete questionnaires, we should survey at about 850 households.

In the 3 regions, a total of 12070 households were interviewed, and the percentage of households in different regions is shown in the Table 1. After excluding 493 (4.08\%) households that did not have complete information, we finally have 11577 households in our study with an overall response rate of $95.92 \%$.

\section{Organization of survey}

The survey was organized by the local Health Bureau in Jiading, Changzhou and Weifang. Investigators consisted of teachers, graduate students and undergraduate students from Fudan University and Weifang Medical College, and local CDC (Center for Disease control) staff. All the investigators were trained before they went to investigate the residents. The residents were interviewed face-to-face at their home. The survey was conducted in July to October in 2008.

We gained approval (IRB\#08-03-0130) for the study from the Medical Research Ethics Committee, School of Public Health, Fudan University (IRB00002408\&FWA 00002399).

\section{Measures and questionnaire}

We, using a structured questionnaire (see Additional file 1), conducted face-to-face interviews. The questionnaire consisted of three parts: (1) household member's age, sex, marital status, education level, employment status, health insurance status, and self-reported chronic illness status; (2) the amount of expenses of the household in 2007, covering food, daily necessities, transportation and communication, accommodation, education and entertainment, health care expenses, and other spending, (3) out-of-pocket health care payment including outpatient, hospitalization, and self-care in 2007.

We used annual expenses per capita as an indicator to measure household's living standard. First of all, we used the information about the amount of expenses of the household in 2007, to calculate annual expenses per capita of the household [2]. Secondly, we divided households into five groups based on quintiles of their annual per capita expenses of the household.

We used a method introduced by another study [12] to calculate the incidence of catastrophic medical expenses based on four cut-off levels-equal to or greater than of $40 \%$ of capacity to pay, $30 \%$ of capacity to pay, $20 \%$ of capacity to pay, $10 \%$ of capacity to pay. When we analyzed the determinants of catastrophic medical expenses, we used a high threshold of payments of at least $40 \%$ of a household's capacity of pay. A household's capacity to pay is defined as total expenditure of the household remaining after basic subsistence needs have been met.

Capacity to pay of the ith household is:

$$
C T P=E X P_{i}-S E_{45-55 i}
$$

Subsistence expenditure $\left(S E_{45-55 i}\right)$ is the average food expenditure of households in the 45th to 55th percentile, adjusted for the size of the $i$ th household. For households whose total spending is below the estimated subsistence need, capacity to pay is taken as the observed nonfood spending.

\section{Statistical analysis}

The multi-level logistic model, supported by Stata11.0, was used to analyse factors associated with catastrophic 


\begin{tabular}{|c|c|c|c|}
\hline Variable & Percentage (\%) & Dinoresd & \\
\hline & & & \\
\hline Region & & Other & 5.95 \\
\hline Shanghai & 27.62 & Annual per capita expenses (yuan) & \\
\hline Changzhou & 22.34 & Shanghai & 8656.2 \\
\hline Weifang & 50.13 & Changzhou & 6722.6 \\
\hline Household head's registration status & & Weifang & 4505.7 \\
\hline 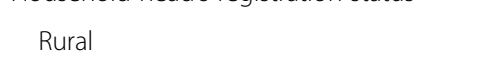 & 68.42 & $\begin{array}{l}\text { Annual per capita out-of-pocket medical expenses } \\
\text { (yuan) }\end{array}$ & \\
\hline Urban & 31.58 & Shanghai & 885.4 \\
\hline Household head's education level & & Changzhou & 632.9 \\
\hline Elementary school or lower & 38.60 & Weifang & 516.9 \\
\hline Middle school & 42.87 & Number of hospitalization in last 12 months & \\
\hline High school & 14.14 & None & 92.12 \\
\hline College or higher & 5.40 & 1 & 7.13 \\
\hline Household head's health insurance status & & 2 & 0.58 \\
\hline Uninsured & 5.75 & 3 or more & 0.16 \\
\hline
\end{tabular}

Household head's having commercial insurance

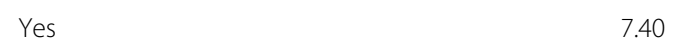

Number of family members with chronic disease

None
1
2
3 or more

Number of family members with an age of 65 or older

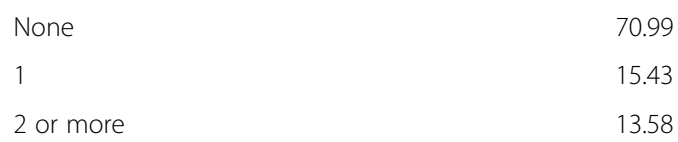

Number of family members younger than 5 years old

$\begin{array}{ll}\text { None } & 86.47 \\ 1 & 13.30 \\ 2 \text { or more } & 0.22\end{array}$

Household size

$\begin{array}{ll}1 & 4.88 \\ 2 & 29.95 \\ 3 & 30.09 \\ 4 \text { or more } & 35.08 \\ \text { Household head's marriage status } & \\ \text { Unmarried } & 2.86\end{array}$

Married medical expenses [13]. Because the households being interviewed were not selected by simple random sampling from the view of all the households, the households in the same region were not independent. Using the multi-level model took into account this potential correlation within group. The dependent variable of the multivariable analysis was a dichotomous variable, indicating whether or not catastrophic medical expenses occurred in a household. If a household's out-of-pocket health care payment exceeded $40 \%$ of the household's capacity-to-pay [12], it was identified as incurring catastrophic medical expenses. Mainly based on literature review $[3,14]$, we defined the independent variables as shown in Table 2. Independent variables included the level-1 variables (the household level variables) and the level-2 variable (the region level variable). Preliminary analysis showed the Variance Inflation Factor (VIF) values of the independent variables being 2.36, indicating that the multicolinearity issue did not exist [15].

In this study, it is more in line with the characteristics of the data to choose the multi-level than the ordinary logistic model. Multi-level model decomposes random error to the corresponding level, and it builds complex error hierarchical structures. Multi-level model has regression equation similar to ordinary regression model, but the residual was decomposed into different hierarchical structures, therefore it can improve the effect of the model fit. In the ordinary regression model, these independent variables are all on the same level, which results in the loss of the information contained in data with hierarchical structures.

The data of this study, it is obviously that the independent variables belong to different levels. For example, the 
Table 2 Dependent variable and independent variables

\begin{tabular}{ll}
\hline Variable & Description \\
\hline Dependent variable & 1 if household incurred \\
& catastrophic medical expenses \\
& 0 otherwise
\end{tabular}

Independent variable

Household level

Household head's residency status 1 - rural, 0 - urban
Household head's ethnicity

Household head's education level

$\begin{array}{ll}\text { Primary school or lower } & \text { Reference } \\ \text { Middle school } & 1 \text { if yes, } 0 \text { otherwise } \\ \text { High school } & 1 \text { if yes, } 0 \text { otherwise } \\ \text { College or higher } & 1 \text { if yes, } 0 \text { otherwise }\end{array}$

Household head's marriage status

Unmarried
Married
Divorced
Other

Household head's social health insurance

Uninsured
Labor insurance
Urban residents insurance
New Cooperative Medical Scheme
(NCMS)

Other social insurance

Household head's private health insurance

Household head's occupation

Manager in government, enterprises and institutions

Private entrepreneurs and managers

Professional and technical personnel

Ordinary administrative in

government, enterprises and

institutions

Employees in business or service industry

Primary businesses

Urban worker

Farmers engaged in non-agricultural labor

Farmer

Unemployed

Tired

Other

Household head's age group

$$
\begin{aligned}
& <25 \text { years } \\
& >=25 \text { and }<30 \text { years } \\
& >=30 \text { and }<35 \text { years }
\end{aligned}
$$

Reference

1 if yes, 0 otherwise

1 if yes, 0 otherwise

1 if yes, 0 otherwise

Reference

1 if yes, 0 otherwise

1 if yes, 0 otherwise

1 if yes, 0 otherwise

1 if yes, 0 otherwise

1 if yes, 0 no

Reference

1 if yes, 0 otherwise

1 if yes, 0 otherwise

1 if yes, 0 otherwise

1 if yes, 0 otherwise

1 if yes, 0 otherwise

1 if yes, 0 otherwise

1 if yes, 0 otherwise

1 if yes, 0 otherwise

1 if yes, 0 otherwise

1 if yes, 0 otherwise

1 if yes, 0 otherwise

Reference

1 if yes, 0 otherwise

1 if yes, 0 otherwise
Table 2 Dependent variable and independent variables (Continued)

$$
\begin{aligned}
& >=35 \text { and }<40 \text { years } \\
& >=40 \text { and }<45 \text { years } \\
& >=45 \text { and }<50 \text { years } \\
& >=50 \text { and }<55 \text { years } \\
& >=55 \text { and }<60 \text { years } \\
& >=60 \text { and }<65 \text { years } \\
& >=65 \text { and }<70 \text { years } \\
& >=70 \text { and }<75 \text { years } \\
& >=75 \text { years }
\end{aligned}
$$

Household head's sex

Number of persons with chronic disease

None

1

1 if yes, 0 otherwise

1 if yes, 0 otherwise

1 if yes, 0 otherwise

1 if yes, 0 otherwise

1 if yes, 0 otherwise

1 if yes, 0 otherwise

1 if yes, 0 otherwise

1 if yes, 0 otherwise

1 if yes, 0 otherwise

1- female, 0-male

Reference

1 if yes, 0 otherwise

1 if yes, 0 otherwise

1 if yes, 0 otherwise

3 or more

Number of persons 65 years old or older

None Reference

1

2 or more

1 if yes, 0 otherwise

Number of persons younger than

5 years old

None Reference

1

2

Number of hospitalizations in last 12 months

None Reference

111 if yes, 0 otherwise

21 if yes, 0 otherwise

$3 \quad 1$ if yes, 0 otherwise

Income quintile

1st (top)living standard quintile Reference

2nd living standard quintile $\quad 1$ if yes, 0 otherwise

3rd living standard quintile $\quad 1$ if yes, 0 otherwise

4th living standard quintile $\quad 1$ if yes, 0 otherwise

5th(bottom)living standard quintile $\quad 1$ if yes, 0 otherwise

Household size

$\begin{array}{ll}1 & \text { Reference } \\ 2 & 1 \text { if yes, } 0 \text { otherwise } \\ 3 & 1 \text { if yes, } 0 \text { otherwise } \\ 4 \text { or more } & 1 \text { if yes, } 0 \text { otherwise }\end{array}$

Area level

Shanghai Reference

Changzhou 1 if yes, 0 otherwise

Weifang 1 if yes, 0 otherwise
1 if yes, 0 otherwise 
viable "family member older than $65 y$ " is a householdlevel variable, however, the variable "region" is an area level one, which represents the general situation of the region's socio-economic status. Due to lack of more detailed data on region, this study uses the integrated variable "region", which in fact reflects the differences among regions in terms of medical services price, culture background, health insurances and other information. In China, even the same health insurance, such as New Rural Cooperative Medical, the extent of compensation in different regions is usually different [4]. Based on the characteristics of the data of this study, it is more suitable to use the multi-level model which reflects the hierarchy of the data.

\section{Results}

Household characteristics and out-of-pocket medical expenses are displayed in Table 1. Among the total of 11,577 households, $68.42 \%$ were located in rural areas, $29.39 \%$ had one or more persons with chronic disease(s), $29.01 \%$ had one or more persons with an age of 65 or older, and $13.52 \%$ had one or two children younger than 5 years old. Further, $7.87 \%$ of the households had at least one person being hospitalized in the last 12 months. Annual per capita out-of-pocket medical expenses were 885.4 yuan, 632.9 yuan, and 516.9 yuan, accounting for $10.23 \%, 9.41 \%$ and $11.47 \%$ of annual total expenses, in Shanghai, Changzhou, and Weifnag, respectively.

Based on availability of public data, we compared the annual per capita income in this study and public data as shown Table 3, which showed that indicators in this study were similar to the public data except a little difference.

Table 4 shows the incidence of catastrophic medical expenses based on the four cut-off levels. At the $40 \%$ level, $9.24 \%-24.79 \%$ of the households incurred catastrophic medical expenses that varied across different areas. Urban areas of Shanghai had the lowest incidence whereas rural areas of Shandong had the highest. At the $40 \%$ cut-off level, the $4^{\text {th }}$ quintile had the highest incidence of catastrophic medical expenses and the $2^{\text {nd }}$ quintile had the lowest.

Table 3 Comparison of annual per capita income in this sample and public data (yuan)

\begin{tabular}{lll}
\hline Group of households & Sample data & Public data \\
\hline Urban Shanghai & 19291 & $19770^{*}$ \\
Rural Shanghai & 11502 & $11416^{*}$ \\
Rural Changzhou & 10908 & $10171^{* *}$ \\
Urban Weifang & 12922 & $13476^{* * *}$ \\
Rural Weifang & 6151 & $6278^{* * *}$ \\
\hline
\end{tabular}

*Public data are from: Report of National Economic and Social Development in 2007 (http://tjj.jiading.gov.cn/website/pages/content_0.htm?channel=23\&id=28). **Public data from: Report of National Economic and Social Development Indicators in 2007 (http://www.cztjj.gov.cn/node/tjsj_2/2011-8-18/1856031655. html).

***Public data are from: Shandong Statistical Yearbook in 2007 (http://www. stats-sd.gov.cn/tjjj/nj2008/indexch.htm).
Table 4 Incidence of catastrophic medical expenses by different cut-offs (\%)

\begin{tabular}{|c|c|c|c|c|}
\hline & \multicolumn{4}{|c|}{$\begin{array}{l}\text { Out-of-pocket medical expenses as a percentage } \\
\text { of total non-food expenses }\end{array}$} \\
\hline & $>=40 \%$ & $>=30 \%$ & $>=20 \%$ & $>=10 \%$ \\
\hline \multicolumn{5}{|l|}{ Area } \\
\hline Shanghai - urban & 7.64 & 12.39 & 19.37 & 37.39 \\
\hline Shanghai - rural & 11.48 & 17.55 & 27.15 & 47.02 \\
\hline Changzhou - rural & 11.61 & 15.57 & 23.18 & 41.75 \\
\hline Weifang - urban & 13.64 & 20.16 & 29.99 & 49.34 \\
\hline Weifang - rural & 22.95 & 30.07 & 40.47 & 58.42 \\
\hline \multicolumn{5}{|l|}{ Income level } \\
\hline Top quintile & 10.84 & 14.46 & 18.65 & 32.9 \\
\hline $2^{\text {nd }}$ quintile & 9.24 & 14.43 & 23.11 & 40.65 \\
\hline $3^{\text {rd }}$ quintile & 11.06 & 17.07 & 26.66 & 47.93 \\
\hline $4^{\text {th }}$ quintile & 24.79 & 31.49 & 40.60 & 60.3 \\
\hline Bottom quintile & 21.06 & 28.53 & 41.82 & 61.16 \\
\hline Total & 15.40 & 21.2 & 30.17 & 48.59 \\
\hline
\end{tabular}

Table 5 shows the result of multi-level mode. The whole model is significant as shown in the table. The test of rho shows that region was significantly associated with the incidence of catastrophic medical expenses, which means that households within region were correlated. Most of household-level variables were also significant. As compared to the top income group, the $4^{\text {th }}$ and $5^{\text {th }}$ (bottom) income group were more likely to incur catastrophic medical expenses. Households whose heads were rural residents were more likely to incur catastrophic medical expenses. The level of education of household heads was also negatively associated with catastrophic medical expenses. Households who had one, two, three or more than family members with chronic diseases had high incidence of catastrophic medical expenses. Households who had one or two family members with older than $65 y$ had high incidence of catastrophic medical expenses. Households who had one or two family members younger than 5 years old had high incidence of catastrophic medical expenses. As compared with households whose heads were uninsured, households whose heads had labor insurance coverage were less likely to incur catastrophic medical expenses, while households whose heads had urban resident health insurance or new cooperative medical scheme (NCMS) coverage were comparable in regard to incurring catastrophic medical expenses.

\section{Discussion}

Findings of our study indicate that sociodemographic factors including income and age are important determinants 
Table 5 Determinants of incidence of household catastrophic medical expenses

\begin{tabular}{|c|c|c|}
\hline Variables & OR $(95 \% \mathrm{Cl})$ & P-Value \\
\hline \multicolumn{3}{|l|}{ Income level } \\
\hline $2^{\text {nd }}$ quintile vs top quintile & $0.89(0.71-1.10)$ & 0.281 \\
\hline $3^{\text {nd }}$ quintile vs top quintile & $1.17(0.94-1.44)$ & 0.152 \\
\hline $4^{\text {th }}$ quintile vs top quintile & $3.25(2.68-3.94)$ & 0.000 \\
\hline Poorest quintile vs top quintile & $2.34(1.91-2.85)$ & 0.000 \\
\hline \multicolumn{3}{|l|}{ Household size } \\
\hline 2 vs 1 & $0.77(0.55-1.07)$ & 0.117 \\
\hline 3 vs 1 & $0.50(0.35-0.69)$ & 0.000 \\
\hline 4 vs 1 & $0.45(0.32-0.63)$ & 0.000 \\
\hline $\begin{array}{l}\text { Household head's registration status } \\
\text { (rural vs urban) }\end{array}$ & $1.47(1.17-1.83)$ & 0.001 \\
\hline \multicolumn{3}{|l|}{ Family member with chronic disease } \\
\hline 1 vs 0 & $2.07(1.80-2.38)$ & 0.000 \\
\hline 2 vs 0 & $2.59(2.09-3.21)$ & 0.000 \\
\hline 3 vs 0 & $2.60(1.39-4.86)$ & 0.003 \\
\hline \multicolumn{3}{|l|}{ Hospitalization in the previous year } \\
\hline 1 vs 0 & $4.38(3.65-5.24)$ & 0.000 \\
\hline 2 vs 0 & $4.54(2.59-7.96)$ & 0.000 \\
\hline 3 vs 0 & $\begin{array}{l}25.71(8.11- \\
81.53)\end{array}$ & 0.000 \\
\hline \multicolumn{3}{|l|}{ Family member less than $5 y$} \\
\hline 1 vs 0 & $1.47(1.23-1.76)$ & 0.000 \\
\hline 2 vs 0 & $9.92(4.14-23.76)$ & 0.000 \\
\hline \multicolumn{3}{|l|}{ Family member older than $65 y$} \\
\hline 1 vs 0 & $1.37(1.15-1.62)$ & 0.000 \\
\hline 2 vs 0 & $1.82(1.53-2.16)$ & 0.000 \\
\hline \multicolumn{3}{|l|}{ Household head's marriage status } \\
\hline Married vs not married & $1.68(1.10-2.55)$ & 0.016 \\
\hline Divorced vs not married & $2.67(1.23-5.78)$ & 0.013 \\
\hline Other vs not married & $1.39(0.86-2.27)$ & 0.182 \\
\hline \multicolumn{3}{|l|}{ Household head's education level } \\
\hline Middle school vs primary school or lower & $0.80(0.70-0.92)$ & 0.002 \\
\hline High school vs primary school or lower & $0.75(0.61-0.92)$ & 0.006 \\
\hline $\begin{array}{l}\text { College or higher vs primary school or } \\
\text { lower }\end{array}$ & $0.64(0.42-0.98)$ & 0.038 \\
\hline \multicolumn{3}{|l|}{ Household head's social insurance } \\
\hline Labor insurance vs none & $0.65(0.46-0.90)$ & 0.011 \\
\hline Urban residential insurance vs none & $0.89(0.63-1.26)$ & 0.525 \\
\hline NCMS vs none & $0.99(0.75-1.32)$ & 0.965 \\
\hline Other social insurance vs none & $0.46(0.32-0.67)$ & 0.000 \\
\hline
\end{tabular}

of catastrophic medical expenses, which is consistent with what Shi and colleagues reported in the central and western regions of China [3], as well as with findings in other developing countries $[14,16]$. Nevertheless, we have two findings that are different from those of other studies [3]. Our first finding is that households with members at age of 5 years or younger had much higher risk of incurring catastrophic medical expenses. There are several explanations. It is quite common in China that parents, even in poor families, are willing to seek the best care possible for their children, especially for their young children who are more susceptible to illness [17]. Moreover, with an exception of Shanghai where an inpatient care insurance program for children under 18 is available, no health insurance programs for children exist in other areas [18].

Our second new finding of the non-linear relationship between income level and incurring catastrophic medical expenses is also not consistent with other studies $[3,14,16]$. We found that the residents in the poorest income group do not have the highest incidence of catastrophic medical expenses, which may have several explanations. First, this may result from the unmet need of the poorest families that tend to skip or limit their utilization of health services due to financial barriers. The China's Fourth National Health Services Survey reports that $38 \%$ of patients did not seek outpatient care and $14.9 \%$ of which were due to financial hardship or high prices of medical services in 2008, and it is also reported that $21 \%$ of patients who should be hospitalized were not, $70.3 \%$ of which were due to economic difficulties [18]. Therefore, patients' decisions on health services utilization are strongly affected by their economic capability to pay. The poorest residents often lack adequate financial means to access necessary health services. If people in poverty are unable to seek promptly health services, they can be trapped into a terrible circle of "poverty - > poor health - > poorer. In addition, the incidence of the $2^{\text {nd }}$ income quintile was higher than that of the top income quintile, which is consistent with what Gotsadze and colleagues found in Georgia [14], but is not consistent with results of Shi and colleagues' study in less developed regions in China [3]. A possible explanation is that the patients with top income levels tend to visit hospitals, especially more expensive hospitals housed by more skillful providers and equipped with more advanced technologies and capacities [5].

Our findings also confirm that hospitalization greatly increases possibilities of incurring catastrophic medical expenses among households. In addition, the odds we estimated could be underestimated if there were residents who should be hospitalized did not go to the hospital. Given the fact that inpatient care is expensive nowadays in China [18], hospitalization is a prominent 
factor among all factors that result in catastrophic medical expense. The latest national survey revealed that $6.8 \%$ of the population gets hospitalized each year. Making the matter worse, uninsured populations are even more susceptible to catastrophic medical expenses [18].

Individual health status is another important determinant of catastrophic medical expenses. Households with family members having chronic diseases tend to suffer catastrophic medical expenses. As the latest national health services survey indicates, persons with chronic illnesses have reached to about 260 million in China [18]. High-risk behavior is one of the contributing factors, but increase in aging populations is another important factor. In addition, relatively speaking, more aging populations reside in eastern China than in central and western China [18,19].

Apart from individual factors, we found that region is also associated with the incidence of catastrophic medical expenses. Although eastern China is the most developed regions in the country, variations in catastrophic medical expenses exist due to economic discrepancies within the regions. People in areas with relatively low income (e.g., rural Weifang) have much higher risk of incurring catastrophic medical expenses than their counterparts in areas with higher income levels (e.g., rural Shanghai and Changzhou). There are several explanations but the most important one is probably related to differences in health insurance programs in different areas. For example, despite of being run by the local government, premiums and reimbursement scales of the New Cooperative Medical Scheme programs differ greatly across areas. With similar rates of enrollment in populations, levels of reimbursement vary in different counties, cities, and provinces, which affect the extent of catastrophic medical expenses.

Urban-rural discrepancies in health expenses persist even in relatively developed areas of China. The incidence of catastrophic medical expenses of rural residents remains much higher than that of urban residents. On the one hand, the rural residents' income in general is lower than that of the city residents. On the other hand, urban hospitals are better equipped by medical technology than rural hospitals and rural residents are willing to go to the urban hospitals despite of their higher prices [20].

This study had several limitations. First, we surveyed both urban and rural residents in Shanghai and Weifang but did not survey urban residents in Changzhou due to insufficient funding, but our sample size was large, which enabled us to calculate the incidences of catastrophic medical expenses in rural and urban residents separately. Another limitation is that economic data of villages were not available in our datasets although they were used by other studies [3].
We used multi-level model because the data in this study were characteristic of hierarchical structures,and the results verified that correlation did exist within the group. Multi-level model can reflect the micro-level (household level) and macro-level (area-level) independent variables, which ordinary logistic model cannot do. Therefore, as to the hierarchy data, we should use a multi-level model.

Such a large-scale survey with a response rate over 95\% could not be completed without the support of the local government. It is similar to the National Health Services Survey (NHSS). In China, the NHSS has been done every five years throughout the China, with response rates above 95\% [21], which is also contributed to the support from the central and local government.

\section{Conclusions}

In conclusion, the occurrence of catastrophic medical expenses among Chinese populations is associated with such factors as family with special member, family income, health services utilization, health insurance coverage, family members' general health status, and regional socioeconomic variations. According to the results, we can adopt some intervention to reduce catastrophic medical expenses.

Firstly, based on the fact that household with members with special age has high risk is a determinant, we can establish targeted health insurance for the special residents such as old residents or very young children.

Secondly, it will be effective way to improve individual health status to reduce use of health services, especially hospitalization according to the result that households with member who hospitalized or suffered chronic diseases were vulnerable to incur catastrophic medical expenses. It is reported that health education can help people form healthy behavior, which will lead to better health status $[22,23]$. Policy can encourage these health education programs. It is extremely important to take effective intervention measures to ensure patients to receive timely, affordable, and high-quality health care to control and avoid deterioration of their diseases, which will prevent avoidable hospitalizations.

Finally, the result that discrepancies exist in different regions even all the regions are within the developed eastern China shows that it remains challenging according to improving equalization in different regions. Take New Cooperative Medical Scheme for example, it needs to be realized that a mere improvement in coverage is not sufficient, and it is more important to improve the level compensation in the future. The New Cooperative Medical Scheme has achieved the coverage of $90 \%$ or higher [18], but the level of compensation varies greatly across areas and is not high in most areas in rural China. Given the current high proportion of out-of-pocket payment [24], a more important step is to increase the level of reimbursement. 


\section{Additional file}

Additional file 1: Questionnaire related to this article.

\section{Competing interests}

The authors declare that they have no competing interests.

\section{Authors' contributions}

$\mathrm{XL}$ participated in design of study, data analysis and interpretation, statistical methods, manuscript draft. JS participated in statistical methods, interpretation and manuscript draft. $J$ participated in design and concept of study, interpretation and acquisition of data. YW participated in concept of the study and interpretation. MS participated in interpretation and acquisition of data. CL participated in interpretation and acquisition of data. FC participated in acquisition of data. $\mathrm{MH}$ participated in design and concept of study, acquisition of data, acquisition of funding, and supervision. All authors read and approved the final manuscript.

\section{Acknowledgements}

This study was funded by Major Research Projects from Ministry of Education [07JZD0017], Innovative Research Team in University from Ministry of Education of China [IRT0912], National Natural Science Foundation of China [70733002 and 70903014], Health Research Special Funding from Ministry of Health [201002028], Social Science Research Project from Fudan University"985 project" phaselll [2011SHKXZD020], China Scholarship Council.

\section{Author details}

${ }^{1}$ Research Institute of Health Development Strategies, School of Public Health, Fudan University, Shanghai, China. ${ }^{2}$ Department of Health Care Administration and Policy, University of Nevada, Las Vegas, USA.

Received: 5 August 2012 Accepted: 27 November 2013

Published: 5 December 2013

\section{References}

1. Xu K, Evans DB, Kawabata K, Zeramdini R, Klavus J, Murray CJL: Household catastrophic health expenditure: a multicountry analysis. Lancet 2003, 326:111-117.

2. O'Donnell O, Doorslaer EV, Wagstaff A, Lidelow M: Analysing health equity using household survey data: a guide to techniques and their implementation. Washington, DC: World Bank; 2008.

3. Shi W, Chongsuvivatwong V, Geater A, Zhang J, Zhang H, Brombal D: Effect of household and village characteristics on financial catastrophe and impoverishment due to health care spending in Western and Central Rural China: a multilevel analysis. Health Res Policy Syst 2011, 9:16.

4. Sun X, Jackson S, Carmichael G, Sleigh A: Catastrophic medical payment and financial protection in rural China: evidence from the new cooperative medical scheme in Shandong province. Health Econ 2009, 18:103-119.

5. Wang Y, Chang F, Li X, Lu J, Sun M, Zhu D, Chen Y, Hao M: To eliminate the phenomenon of "seeing a doctor is expensive" and misgivings of the public. Chin Health Res 2011, 1:16-17.

6. National Bureau of Statistics of the People's Republic of China: The Chinese Statistics Annual Book. Beijing: China Statistic Press; 2012.

7. The National Economic and Social Development Statistics annual report in Jiangsu in 2011.. http://www.jssb.gov.cn/2011nj/nj20/nj2007.htm.

8. The National Economic and Social Development Statistics Annual Report in Weifang in 2011. http://www.wf-stats.gov.cn/Article/ShowArticle.asp? ArticlelD=2817.

9. Steps in Applying Probability Proportional to Size (PPS) and Calculating Basic Probability Weights. http://www.who.int/tb/advisory_bodies/ impact_measurement_taskforce/meetings/prevalence_survey/ psws_probability_prop_size_bierrenbach.pdf.

10. Yang S: Health Statistics. Beijing: People's Health Press; 1992.

11. Ying $X$, Jiang $Q$, Liu B, Li G, Hu S, Chen Z, Zhang L: The impact on family health financing fairness from the households suffering from catastrophic expenditures. Chin J Hospital Adm 2004, 8:164-464.

12. Xu K, Evans DB, Carrin G, Aguilar-Rivera AM, Musgrove P, Evans T: Protecting households from catastrophic health spending. Health Aff 2007, 26:972-983.
13. Omar RZ, Thompson SG: Analysis of a cluster randomized trial with binary outcome data using a multi-level model. Statist Med 2000, 19:2675-2688.

14. Gotsadze G, Zoidze A, Rukhadze N: Household catastrophic health expenditure: evidence from Georgia. BMC Health Serv Res 2009, 9:69.

15. Robert $M, O^{\prime}$ brien $A$ : Caution regarding rules of thumb for variance inflation factors. Qual Quant 2007, 41:673-690.

16. Su T, Kouyaté B, Flessa S: Catastrophic household expenditure for health care in a low-income society: a study from Nouna District, Burkina Faso. Bull World Health Organ 2006, 84:21-27.

17. Chen Z: The health status of the left-behind children in rural China. Chin J Popul Sci 2009, 5:95-112.

18. Main Outcomes of China's Fourth National Health Services Survey in 2008. http://www.moh.gov.cn/mohbgt/s6690/200902/39201.shtml.

19. Yang G, Kong L, Zhao W, Wan X, Zhai Y, Chen LC, Koplan JP: Health system reform in China 3: emergence of chronic non-communicable diseases in China. Lancet 2008, 11:372.

20. Liu Y: China's public health-care system: facing the challenges. Bull World Health Organ 2006, 84:1.

21. Meng Q, Xu L, Zhang Y, Qian J, Cai M, Xin Y, Gao J, Xu K, Boerma JT, Barber SL: Trends in access to health services and financial protection in China between 2003 and 2011: a cross-sectional study. Lancet 2012, 3:805-813.

22. World health organization: The world health report 2002. Geneva: World Health Organization; 2002.

23. Wang S, Marquez P, Langenbrunner J: Toward a Healthy and Harmonious Life in China: Stemming the Rising Tide of non-Communicable Diseases. Washington D.C: Human development unit; East Asia and Pacific region. The World Bank. [http://www-wds.worldbank.org/external/default/ WDSContentServer/WDSP/IB/2011/07/25/000333037_20110725011735/ Rendered/PDF/634260WP00Box30official0use0only090.pdf]

24. Wang Y, Shen JJ, Mei S, Moseley CB, Lu J, Lin F, Li X, Chang F, Hao M: Why healthcare became so expensive in China? The transformation of healthcare financing during Chinese economic development. Int J Public Policy 2012, 8:4-20.

doi:10.1186/1472-6963-13-506

Cite this article as: Li et al:: Household catastrophic medical expenses in eastern China: determinants and policy implications. BMC Health Services Research 2013 13:506.

\section{Submit your next manuscript to BioMed Central and take full advantage of:}

- Convenient online submission

- Thorough peer review

- No space constraints or color figure charges

- Immediate publication on acceptance

- Inclusion in PubMed, CAS, Scopus and Google Scholar

- Research which is freely available for redistribution 